\title{
AÇÃo DO IMAZAPIC+IMAZAPYR SOBRE A TIRIRICA (Cyperus rotundus) E OS DESNITRIFICADORES EM MILHO ${ }^{1}$
}

\author{
Action of Imazapic+Imazapyr on Purple Nutsedge (Cyperus rotundus) and Denitrifying Bacteria \\ in Corn
}

ULBRICH, A.V. ${ }^{2}$, LEITE, C.R.F. ${ }^{2}$, SOUZA, J.R.P. ${ }^{3}$ e ANDRADE, D.S. ${ }^{4}$

\begin{abstract}
RESUMO - Os objetivos do experimento foram avaliar a eficácia do imazapic+imazapyr sobre a tiririca e a influência desta planta daninha sobre a população de desnitrificadores em solo cultivado com milho. O experimento foi realizado em caixas de 0,70 x 0,30 x 0,30 m, onde foram semeados o milho tolerante às imidazolinonas (C-901CL) e plantados 50 bulbos de tiririca. O delineamento experimental foi o inteiramente casualizado, com seis repetições. Os tratamentos foram constituidos por: 1 . milho sem tiririca; 2 . milho com tiririca; 3 . milho com tiririca capinada; 4. milho com tiririca e imazapic+imazapyr $\left(63+21 \mathrm{~g} \mathrm{ha}\right.$ h $^{-1}$ de i.a.) em pós-emergência; e 5 . milho com tiririca e imazapic+imazapyr $\left(63+21 \mathrm{~g} \mathrm{ha}^{-1} \mathrm{de}\right.$ i.a.) em préemergência. O herbicida foi eficiente em pós-emergência, diminuindo as manifestações epígeas da tiririca em $41 \%$ e proporcionando controle visual de $88 \%$ aos 21 dias após a aplicação. Os desnitrificadores do solo aumentaram em seis e dez vezes aos 24 e 54 dias após a semeadura do milho, respectivamente, com a presença de tiririca. A aplicação do herbicida em pós-emergência reduziu a população de desnitrificadores para $1,91 \times 10^{5}$ NMP (número mais provável), 89\% menor que a testemunha capinada $\left(16,78 \times 10^{5} \mathrm{NMP}\right)$.
\end{abstract}

Palavras-chave: bactéria, pseudomonas, nitrogênio, volatilização, competição.

\begin{abstract}
The objective of this work was to evaluate the efficacy of imazapic+imazapyr in controling purple nutsedge and its effect on the population of denitrifying bacteria in soil cultivated with corn. The trial was set up in $0.70 \times 0.30 \times 0.30 \mathrm{~m}$ boxes where imidazolinone tolerant corn (C-901CL) was seeded together with 50 purple nutsedge bulbs. The experimental design was randomized with six replications. The treatments were: 1) corn without nutsedge; 2) corn with nutsedge; 3) corn with cut nutsedge; 4) corn with nutsedge treated with imazapic+imazapyr $\left(63+21 \mathrm{~g} \mathrm{ha}^{-1}\right.$ i.a) applied in post-emergence and 5) corn with nutsedge treated with imazapic+imazapyr $\left(63+21 \mathrm{~g} \mathrm{ha}^{-1} \mathrm{i} . \mathrm{a}\right)$, applied in pre-emergence. The herbicide was efficient when applied in post-emergence, reducing in $41 \%$ the setting of aerial parts of the nutsedge with visual control effect of $88 \%$, twenty-one days after spraying. The soil denitrifying bacteria increased sixand ten-fold, 24 and 54 days after corn seeding, respectively, in the presence of purple nutsedge. The application in post-emergence reduced the denitrifying population to $1.91 \times 10^{5} \mathrm{MPN}$ (most

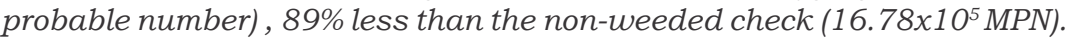

Key words: bacteria, pseudomonas, nitrogen, volatilization, competition.

Recebido para publicação em 1.4.2004 e na forma revisada em 17.12.2004.

Pós-graduando em Agronomia, nível de doutorado, Dep. de Agronomia, CCA, Universidade Estadual de Londrina - UEL, Caixa Postal 6001, 86051-990 Londrina-PR, <adolfo.ulbrich@basf-sa.com.br>. ${ }^{3}$ Professor Adjunto, Dep. de Agronomia, CCA, UEL, <jose@uel.br>. ${ }^{4}$ Pesquisadora do Instituto Agronômico do Paraná, Microbiologia de Solo, Caixa Postal 481, 86047-902 Londrina-PR, <diva@pr.gov.br>. 


\section{INTRODUÇÃO}

O nitrogênio é considerado um dos principais nutrientes para as plantas; na cultura do milho, ele pode aumentar a produtividade e o teor de proteína dos grãos. Ele pode ser proveniente da mineralização da matéria orgânica, fixação biológica, adubação nitrogenada e chuva. No que se refere à reposição do nitrogênio do solo consumido pelas plantas cultivadas ou perdidas por volatilização, lixiviação e erosão, não existem ainda critérios definidos para que ela seja feita após a análise do solo (Yamada, 1995). Essa situação tem despertado o interesse por estudos envolvendo sua dinâmica nos agroecossistemas, reforçado pela crescente demanda por alimentos e pelo aumento da população mundial.

Dentre as perdas de $\mathrm{N}$, a que ocorre na forma de gases (10-80\%) liberados na atmosfera por causa da volatilização da amônia e pela desnitrificação é uma das principais. Espécies de bactérias habitantes do solo são capazes de realizar a desnitrificação: redução do nitrato a nitrito e deste em gases nitrogenados, como NO, $\mathrm{N}_{2} \mathrm{O}$ e $\mathrm{N}_{2}$ (Yamada, 1996). A desnitrificação biológica no solo $\left(\mathrm{NO}_{3}{ }^{-} \rightarrow \mathrm{NO}_{2}{ }^{-}\right.$ $\rightarrow\left[\begin{array}{ll}\mathrm{Enz} & \mathrm{NO}\end{array}\right] \rightarrow \mathrm{N}_{2} \mathrm{O} \rightarrow \mathrm{N}_{2}$ ) é um processo metabólico específico realizado por limitado número de gêneros de bactérias, na sua maioria quimiorganotróficas e anaeróbicas facultativas (Tiedje, 1982). Dentre elas são citadas espécies do gênero Pseudomonas, a exemplo de $P$. fluorescens e $P$. alcaligenes, tipicamente desnitrificadoras (Gamble et al., 1977), e as fixadoras de nitrogênio, pertencentes aos gêneros Rhizobium e Azospirillum. Nesse processo, os substratos comuns são o nitrato $\left(\mathrm{NO}_{3}\right)$ e o nitrito $\left(\mathrm{NO}_{2}^{-}\right)$. Como desnitrificadores, esses microrganismos exercem função importante no ciclo do nitrogênio no solo, reduzindo óxidos de $\mathrm{N}$ para formas gasosas, as quais são liberadas na atmosfera. A desnitrificação tem significativa importância para a agricultura, uma vez que pode reduzir a disponibilidade de $\mathrm{N}$ em culturas de interesse econômico (Aulakh et al., 1992).

Certas condições de solo, como elevados teores de matéria orgânica, compactação e anaerobiose, podem contribuir para o aumento da atividade das bactérias (Okafor \& Datta, 1976). Paramasivam et al. (1999) constataram alta correlação entre o número mais provável de desnitrificadores no solo e a capacidade de desnitrificação deste, observando perdas de $\mathrm{N}$ na forma de nitrito $\left(\mathrm{N}_{2} \mathrm{O}\right)$ da ordem de 0,2 a $1,4 \mathrm{mg} \mathrm{g}^{-1}$ de solo para uma população entre $0,1 \times 10^{3}$ a $2,25 \times 10^{5} \mathrm{NMP}$.

Segundo Volz (1977), as raízes de plantas do gênero Cyperus podem aumentar a atividade de bactérias desnitrificadoras, com conseqüente diminuição da disponibilidade de N. Patterson (1985) observou que Cyperus esculentus consorciado com milho para silagem reduz os teores de matéria seca e de nitrogênio total do milho. Verificou ainda que, do total de $\mathrm{N}$ reduzido da cultura, apenas 38\% foi aproveitado pela planta daninha. Na competição entre plantas cultivadas e daninhas, o $\mathrm{N}$ é um dos elementos mais exigidos e com maior nivel de competição (Escosteguy et al., 1997).

Yamada \& Abdalla (2000) verificaram que a planta de milho tem preferência por fertilizantes hidrossolúveis e que o íon amônio $\left(\mathrm{NH}_{4}^{+}\right)$é utilizado na cultura preferencialmente nos primeiros estádios de desenvolvimento, e o ion nitrato $\left(\mathrm{NO}_{3}^{-}\right)$, nos estádios finais; mais de $50 \%$ do $\mathrm{N}$ utilizado pelo milho é absorvido após o florescimento.

Os experimentos de Mello et al. (1988) e Rodrigues \& Kiehl (1986) demonstraram que, em áreas muito infestadas por plantas da espécie $C$. rotundus, as adubações nitrogenadas podem apresentar baixa eficiência, sendo esta influenciada pela forma de $\mathrm{N}$ e pela época da aplicação. Assim, para obter os beneficios da adubação nitrogenada em milho cultivado em solo com $C$. rotundus são necessários alguns cuidados práticos, como a combinação de formas de $\mathrm{N}$ com as épocas de aplicação, em que a forma nítrica $\left(\mathrm{NO}_{3}{ }^{-}\right)$seria aplicada na fase inicial do desenvolvimento da cultura e a forma amoniacal $\left(\mathrm{NH}_{4}^{+}\right)$na fase final, após o florescimento do milho, uma vez que a desnitrificação é mais acentuada com a forma nítrica.

Outra alternativa para aumentar a disponibilidade de $\mathrm{N}$ às plantas de milho é a aplicação de herbicidas que diminuam a população de C. rotundus. Almeida et al. (2002) relatam que até pouco tempo não havia produtos eficientes sobre esta planta daninha que 
fossem seletivos ao milho, porém, com o recém-aparecimento do milho tolerante ao grupo químico das imidazolinonas, tornou-se possivel a utilização de herbicidas altamente eficientes no controle da tiririca, como, por exemplo, o Onduty ${ }^{\circledR}$ (marca registrada BASF S.A.), mistura formulada de imazapic e imazapyr (525+175 $\mathrm{g} \mathrm{kg}^{-1}$ de i.a.). Os herbicidas deste grupo químico inibem a sintese da enzima acetolactato sintase (ALS), impedindo a sintese dos aminoácidos valina, leucina e isoleucina, essenciais para as plantas (Rodrigues \& Almeida, 1998).

Com base nesses fundamentos de literatura, os objetivos do presente estudo foram avaliar a eficácia da aplicação da mistura pronta do herbicida imazapic + imazapyr na cultura do milho infestado por tiririca (C. rotundus) e na população de bactérias desnitrificadoras do solo.

\section{MATERIAL E MÉTODOS}

O presente experimento foi conduzido em campo na Universidade Estadual de Londrina, Londrina-PR, com latitude de $23^{\circ} 15^{\prime} \mathrm{S}$, longitude de $51^{\circ} 10^{\prime} \mathrm{W}$ e clima Cfa, segundo a escala de Köeppen.

O solo do experimento foi classificado como Latossolo Vermelho distrófico, textura argilosa, com 74\% de argila, pH 6,0 em $\mathrm{CaCl}_{2}$, $36,53 \mathrm{~g} \mathrm{dm}^{-3}$ de matéria orgânica, $8,02 \mathrm{~g} \mathrm{dm}^{-3}$ de CTC, 21,43 $\mathrm{mg} \mathrm{dm}^{-3}$ de $\mathrm{P}$ e 70,1\% em saturação de bases. O solo foi retirado da camada arável de área cultivada com aveiapreta durante o inverno e colocado em caixas de concreto de 0,70 m comprimento, 0,30 m de largura e 0,30 $\mathrm{m}$ de profundidade. Cada caixa constituiu uma parcela. Inicialmente, foi determinado o NMP de microrganismos desnitrificadores em amostra de $200 \mathrm{~g}$ do solo coletado.

O delineamento experimental foi o inteiramente ao acaso, com cinco tratamentos e seis repetições. Os tratamentos foram: T1) milho cultivado sem tiririca; T2) milho cultivado com tiririca; T3) milho cultivado com tiririca capinada; T4) milho cultivado com tiririca e aplicação de imazapic+imazapyr na dose de $63+21 \mathrm{~g}$ ha $^{-1-}$ de i.a. em pós-emergência; e T5) milho cultivado com tiririca e aplicação de imazapic+imazapyr na dose de $63+21 \mathrm{~g} \mathrm{ha}^{-1}$ de i.a. em pré-emergência.

Em cada parcela dos tratamentos T2, T3, T4 e T5 foram plantados 50 tubérculos viáveis de tiririca seis dias antes da semeadura (DAS) do milho a $0,10 \mathrm{~m}$ de profundidade. Os tubérculos foram coletados de uma área próxima momentos antes do plantio. Em 20/12/2000 foi realizada a semeadura do milho-híbrido reagente C- $901 \mathrm{CL}$. O tratamento com herbicida na modalidade de pré-emergência (PRÉ) foi aplicado logo após a semeadura do milho e em pós-emergência (PÓS), aos 21 DAS, quando as plantas de milho se encontravam no estádio de três a quatro folhas. Foram aplicados $60 \mathrm{~kg} \mathrm{ha}^{-1}$ de nitrogênio na forma de nitrato de cálcio em todos os tratamentos, aos 21 dias após o plantio da tiririca.

As aplicações da mistura pronta do herbicida para os tratamentos T4 e T5 foram feitas com pulverizador costal propelido a $\mathrm{CO}_{2}$, pressão constante de $150 \mathrm{kPa}$, equipado de "pistola", um bico leque da série Teejet tipo XR 110:02, a 0,35 $\mathrm{m}$ acima do alvo. A faixa de pulverização foi de 0,40 $\mathrm{m}$ de largura, totalizando volume de $200 \mathrm{~L} \mathrm{ha}^{-1}$.

Aos 8, 15, 22, 28, 35 e 42 DAS, foram realizadas as avaliações visuais do controle de tiririca e toxicidade nas plantas de milho e foi feita a contagem do número de manifestações epígeas da tiririca. Para as avaliações visuais, foram atribuídas notas de 0 a $100 \%$, em que 0 corresponde à ausência de controle ou injúria e 100 ao controle total das plantas daninhas ou morte das plantas de milho (SBCPD, 1995).

Para a determinação do NMP de microrganismos desnitrificadores do solo, foram coletadas amostras com 200 g de solo de cada parcela aos 24 e 54 DAS, empregando-se a técnica descrita por Tiedje (1982). Nessas mesmas épocas também foi determinada a umidade de cada amostra. As amostras de solo foram passadas por peneira de $2 \mathrm{~mm} e$ armazenadas a temperatura de $-4^{\circ}$ a $-6^{\circ} \mathrm{C}$, até a realização da análise, para a qual foram realizadas suspensões de solo, preparadas a partir de $10 \mathrm{~g}$ de solo úmido, $95 \mathrm{~mL}$ de solução salina e "pérolas de vidro" e centrifugação a 200 rpm durante 30 minutos. A solução salina foi preparada com água deionizada esterilizada em autoclave a $121^{\circ} \mathrm{C}, 1,5$ atm durante 
20 minutos, e adição dos seguintes sais em $\mathrm{g} \mathrm{L}^{-1}$ : 0,05 de $\mathrm{MgSO}_{4}$ 0,025 de NaCl; 0,1392 de $\mathrm{K}_{2} \mathrm{HPO}_{4}$ e 0,0272 de $\mathrm{KH}_{2} \mathrm{PO}_{4}$. Ao final do preparo da solução procedeu-se ao ajuste para pH 7,3. Em seguida, transferiu-se $1 \mathrm{~mL}$ dessa suspensão para tubo esterilizado contendo $9 \mathrm{~mL}$ de solução salina (diluição $10^{-2}$ ); o processo continuou até a diluição $10^{-5}$. A partir da diluição serial foram inoculados quatro tubos por diluição, contendo $900 \mu \mathrm{L}$ de meio de cultura líquido (3,0 g de extrato de carne; 5,0 g de peptona; 0,5 g de $\mathrm{KNO}_{3}$, em $1.000 \mathrm{~mL}$ de $\mathrm{H}_{2} \mathrm{O}, \mathrm{pH}$ ajustado para 6,8$)$. O meio de cultura - após esterilizado em autoclave a $121{ }^{\circ} \mathrm{C}$ e 1,5 atm durante 20 minutos - foi distribuído assepticamente em tubos eppendorf também autoclavados, sendo estes inoculados com as suspensões diluídas de solo. Depois de inoculados, os tubos foram incubados por 14 dias em condições anaeróbicas, a $28^{\circ} \mathrm{C}$ e na ausência de luz. Após incubação, procedeu-se à verificação da presença de desnitrificadores, identificada pela presença ou ausência de $\mathrm{NO}_{3}{ }^{-}$ e $\mathrm{NO}_{2}^{-}$; para isso, uma aliquota de $100 \mu \mathrm{L}$ do meio de cultura inoculado foi transferida para a placa de teste e a este foram adicionadas de três a seis gotas do reagente de diphenilamine (50 mg de diphenylamina dissolvidos em $25 \mathrm{~mL}$ de $\mathrm{H}_{2} \mathrm{SO}_{4}$ concentrado). $\mathrm{O}$ aparecimento da cor azul na superficie indica a presença de $\mathrm{NO}_{3}^{-} \mathrm{e}$ $\mathrm{NO}_{2}^{-}$(ausência de desnitrificadores), e a ausência de coloração (incolor) evidencia a desnitrificação (presença de microrganismos desnitrificantes). A partir dos resultados positivos e negativos de presença de microrganismos para cada uma das diluições das suspensões inoculadas, procedeu-se ao cálculo da estimativa do número de microrganismos desnitrificantes nas amostras, utilizando valores encontrados em tabelas (Andrade \& Hamakawa, 1994). Os dados obtidos foram transformados para solo seco.

Os dados coletados foram submetidos à análise de variância, e a comparação entre as médias foi feita pelo teste de Tukey a 5\% de significância.

\section{RESULTADOS E DISCUSSÃO}

Nas manifestações epígeas da tiririca foi observada uma evolução variável de 53 manifestações aos 8 DAS e até 132 aos 42 DAS (Tabela 1). A aplicação da mistura pronta (imazapic + imazapyr) em pós-emergência (PÓS) foi mais eficiente que aquela em préemergência (PRÉ) (Tabelas 1 e 2). A redução das manifestações epígeas da tiririca aos 42 DAS foi de $41 \%$ na aplicação em PÓS e 18\% em PRÉ, sendo essa diferença não-significativa. Considerando que o mecanismo de ação do herbicida imazapic+imazapyr é a inibição da enzima acetolactato sintase (ALS), provavelmente as plantas de tiririca tiveram a paralisação no crescimento após a aplicação do herbicida e apresentaram necroses a partir do meristema apical, sem, no entanto, chegarem à morte durante o período de avaliação do experimento.

A eficácia do herbicida no controle da tiririca avaliada visualmente foi maior em pósemergência, chegando a $88 \%$ aos 42 DAS, enquanto em pré-emergência o controle não

Tabela 1 - Número de manifestações epígeas de tiririca (C. rotundus) emergidas nos diferentes tratamentos aplicados ao experimento. Londrina, 2003

\begin{tabular}{|c|c|c|c|c|c|c|c|}
\hline \multirow{3}{*}{ Tratamento } & $\mathrm{DASM}^{3 /}$ & 8 & 15 & 22 & 28 & 35 & 42 \\
\hline & DAAPE $^{4 /}$ & 8 & 15 & 22 & 28 & 35 & 42 \\
\hline & $\mathrm{DAAPO}^{\underline{5}}$ & - & - & 01 & 07 & 14 & 21 \\
\hline Milho & & $0^{1 /} \mathrm{b}^{2 /}$ & $0 \mathrm{~b}$ & $0 \mathrm{~b}$ & $0 \mathrm{c}$ & $0 \mathrm{c}$ & $0 \mathrm{c}$ \\
\hline Milho + tiririca & & $53,2 \mathrm{a}$ & 74,8 a & $82,7 \mathrm{a}$ & $103,0 \mathrm{a}$ & $111,0 \mathrm{a}$ & $131,7 \mathrm{a}$ \\
\hline Milho + tiririca capinada & & $0 \mathrm{~b}$ & $0 \mathrm{~b}$ & $0 \mathrm{~b}$ & $0 \mathrm{c}$ & $0 \mathrm{c}$ & $0 \mathrm{c}$ \\
\hline Milho + tiririca + imazapic + imazapyr (PÓS) & & $53,7 \mathrm{a}$ & $72,8 \mathrm{a}$ & 79,3 a & $79,3 \mathrm{~b}$ & $77,5 \mathrm{~b}$ & $77,8 \mathrm{~b}$ \\
\hline Milho + tiririca + imazapic + imazapyr (PRÉ) & & $58,7 \mathrm{a}$ & $80,0 \mathrm{a}$ & $89,2 \mathrm{a}$ & $100,3 \mathrm{ab}$ & $104,5 \mathrm{a}$ & $108,0 \mathrm{a}$ \\
\hline \multicolumn{2}{|l|}{ CV (\%) } & 20,2 & 23,5 & 23,4 & 23,3 & 23,4 & 22,8 \\
\hline
\end{tabular}

${ }^{1 /}$ Dados originais sem transformação; ${ }^{2 /}$ médias seguidas pela mesma letra na coluna não diferem entre si pelo teste de Tukey a 5\% de probabilidade; ${ }^{3 /}$ DASM = dias após a semeadura do milho; ${ }^{4 /}$ DAAPE = dias após a aplicação do herbicida em pré-emergência; ${ }^{5 /} \mathrm{DAAPO}=$ dias após a aplicação do herbicida em pós-emergência. 
passou de 46\% na mesma data de avaliação (Tabela 2).

Os dados de contagem da população de bactérias desnitrificadoras do solo antes e após o plantio da tiririca são apresentados na Tabela 3 e na Figura 1. A população inicial de desnitrificadores determinada antes do plantio da tiririca foi de $2,48 \times 10^{5} \mathrm{NMP}$ de células por grama de solo seco. Na primeira avaliação, aos 24 DASM, foi observado efeito positivo da presença de tiririca na população desses microrganismos, cuja variação foi de 2,40 a $15,49 \times 10^{5} \mathrm{NMP}^{-1}$ de solo seco, respectivamente para os tratamentos sem tiririca e com tiririca. O aumento da população das bactérias desnitrificadoras foi em média seis vezes maior em função da presença da tiririca nesta época. Aos 54 DAS, o NMP de bactérias desnitrificadoras no solo aumentou de 1,62 para
$10,47 \times 10^{5} \mathrm{NMP} \mathrm{g}^{-1}$ de solo seco, respectivamente para os tratamentos sem tiririca e com tiririca capinada.

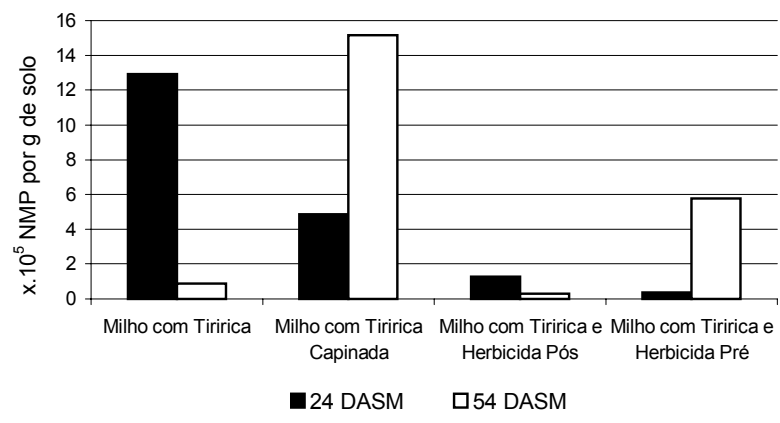

Figura 1 - Aumento da população de bactérias desnitrificadoras no solo em relação ao tratamento com milho e sem tiririca. Londrina, 2003.

Tabela 2 - Porcentagem de controle de tiririca (C. rotundus) entre 8 e 42 dias após a semeadura do milho (DASM) com a aplicação dos tratamentos. Londrina, 2003

\begin{tabular}{|l|c|c|c|c|c|c|c|}
\hline \multirow{2}{*}{ Tratamento } & DASM $^{3 /}$ & 8 & 15 & 22 & 28 & 35 & 42 \\
\cline { 2 - 8 } & DAAPE $^{4 /}$ & 8 & 15 & 22 & 28 & 35 & 42 \\
\cline { 2 - 8 } & DAAPO $^{5 /}$ & - & - & 01 & 07 & 14 & 21 \\
\hline Milho & & $100,0^{1 /} \mathrm{a}^{2 /}$ & $100,0 \mathrm{a}$ & $100,0 \mathrm{a}$ & $100,0 \mathrm{a}$ & $100,0 \mathrm{a}$ & $100,0 \mathrm{a}$ \\
\hline Milho + tiririca & & $0,0 \mathrm{c}$ & $0,0 \mathrm{c}$ & $0,0 \mathrm{c}$ & $0,0 \mathrm{~d}$ & $0,0 \mathrm{~d}$ & $0,0 \mathrm{~d}$ \\
\hline Milho + tiririca capinada & & $100,0 \mathrm{a}$ & $100,0 \mathrm{a}$ & $100,0 \mathrm{a}$ & $100,0 \mathrm{a}$ & $100,0 \mathrm{a}$ & $100,0 \mathrm{a}$ \\
\hline Milho + tiririca + imazapic + imazapyr (PÓS) & & $0,0 \mathrm{c}$ & $0,0 \mathrm{c}$ & $0,0 \mathrm{c}$ & $39,1 \mathrm{~b}$ & $66,7 \mathrm{~b}$ & $87,6 \mathrm{~b}$ \\
\hline Milho + tiririca + imazapic + imazapyr (PRÉ) & & $11,6 \mathrm{~b}$ & $14,9 \mathrm{~b}$ & $17,4 \mathrm{~b}$ & $24,1 \mathrm{c}$ & $34,9 \mathrm{c}$ & $45,8 \mathrm{c}$ \\
\hline \multicolumn{2}{|c|}{ CV (\%) } & 2,51 & 2,84 & 2,26 & 2,95 & 3,21 & 2,23 \\
\hline
\end{tabular}

1/ Dados originais sem transformação; ${ }^{2 /}$ médias seguidas pela mesma letra na coluna não diferem entre si pelo teste de Tukey a $5 \%$ de probabilidade; ㄹ/ DASM = dias após a semeadura do milho; ${ }^{4 /}$ DAAPE = dias após a aplicação do herbicida em pré-emergência; 5/ DAAPO = dias após a aplicação do herbicida em pós-emergência.

Tabela 3 - Número médio de bactérias desnitrificadoras do solo presentes aos 24 e 54 dias após a semeadura do milho (DASM) nos diferentes tratamentos aplicados. Londrina, 2003

\begin{tabular}{|c|c|c|c|c|}
\hline \multirow[b]{2}{*}{ Tratamento } & \multicolumn{2}{|c|}{24 DASM } & \multicolumn{2}{|c|}{54 DAMS } \\
\hline & $\begin{array}{c}\text { Desnitrificador } \\
\left(\log _{10} \mathrm{NMP} \mathrm{g}^{-1}\right)\end{array}$ & $\begin{array}{c}\text { Umidade do Solo } \\
(\%)\end{array}$ & $\begin{array}{c}\text { Desnitrificador } \\
\left(\log _{10} \mathrm{NMP} \mathrm{g}^{-1}\right)\end{array}$ & $\begin{array}{c}\text { Umidade do Solo } \\
(\%)\end{array}$ \\
\hline Milho & $5,38^{1 /} b^{2 /}$ & $17,1 \pm 2,8$ & $5,21 \mathrm{c}$ & $25,4 \pm 1,0$ \\
\hline Milho + tiririca & $6,19 \mathrm{a}$ & $18,0 \pm 0,5$ & $5,40 \mathrm{bc}$ & $26,0 \pm 1,6$ \\
\hline Milho + tiririca capinada & $5,85 \mathrm{a}$ & $17,6 \pm 1,2$ & $6,02 \mathrm{a}$ & $30,5 \pm 1,9$ \\
\hline Milho + tiririca + imazapic + imazapyr (PÓS) & $5,50 \mathrm{~b}$ & $18,0 \pm 1,9$ & $5,29 \mathrm{c}$ & $26,2 \pm 3,8$ \\
\hline Milho + tiririca + imazapic + imazapyr (PRÉ) & $5,42 \mathrm{~b}$ & $17,7 \pm 0,8$ & $5,84 \mathrm{~b}$ & $26,1 \pm 1,4$ \\
\hline CV (\%) & 5,67 & & 1,90 & \\
\hline Coeficiente de correlação (Pearson) $\mathrm{p}<0,01$ & & 0,535 & & $0,894^{* *}$ \\
\hline
\end{tabular}

${ }^{1 /}$ Valores representam médias de seis repetições; ${ }^{2 /}$ médias seguidas pela mesma letra na coluna não diferem entre si pelo teste de Tukey a $1 \%$ de probabilidade. 
Com relação à umidade média do solo para cada tratamento, foi observada correlação positiva $(r=0,89 * *)$ entre a quantidade de água no solo e a população de desnitrificadores em cada tratamento (Tabela 3).

Os resultados obtidos sugerem que o emprego de herbicidas eficientes em áreas com alta infestação de tiririca pode levar à redução das perdas de $\mathrm{N}$ do solo, devido à redução na população de desnitrificadores. Resultados semelhantes foram encontrados por Tenuta \& Beauchamp (1996), os quais observaram reduções de 20 a 30 vezes na taxa (mg N dia ${ }^{-1}$ ) de desnitrificação com a aplicação do herbicida glyphosate em áreas infestadas com Bromus inermis e Poa pratensis.

\section{LITERATURA CITADA}

ALMEIDA, J. C. V.; LEITE, C. R. F.; ULBRICH, A. V. Controle de Cyperus rotundus na cultura do milho Clearfield com o herbicida Onduty (imazapic+imazapyr). In: CONGRESSO BRASILEIRO DA CIÊNCIA DAS PLANTAS DANINHAS, 23., 2002, Gramado. Resumos.. Gramado: Sociedade Brasileira de Controle das Plantas Daninhas, 2002. p. 217.

ANDRADE, D. S.; HAMAKAWA, P. J. Estimativa do número de células de rizóbio no solo e inoculantes por infecção em planta. In: HUNGRIA, M.; ARAUJO, R. S. (Eds.). Manual de métodos empregados em estudos de microbiologia agrícola. Brasília: EMBRAPA-SPI, 1994. p. 63-94.

AULAKH, M. S.; DORAN, J. W.; MOSIER, A. R. Soil denitrification - Significance, measurement, and effects of management. In: Advances in soil science. New York: Springer-Verlag, 1992. p. 1-57.

ESCOSTEGUY, P. A. V.; RIZZARDI, M. A.; ARGENTA, G. Doses e épocas de aplicação de nitrogênio em cobertura na cultura do milho em duas épocas de semeadura. R. Bras. Ci. Solo, v. 21, p. 71-77, 1997.

GAMBLE, T. N.; BETLACH, M. R.; TIEDJE, J. M. Numerically dominant denitrifying bacteria from world soils. Appl. Environ. Microbiol., v. 33, p. 926-939, 1977.

MELLO, F. A. F. et al. Efeito de doses e modos de aplicação de uréia na produção de milho. R. Bras. Ci. Solo, v. 12, p. $269-274,1988$
OKAFOR, L. I.; DATTA, S. K. Competition between upland rice and purple nutsedge for nitrogen, moisture, and light. Weed Sci., v. 24, p. 43-48, 1976.

PARAMASIVAM, S. et al. Denitrification in the vadose zone and in superficial groundwater of a sandy entisol with citrus production. Plant Soil, v. 208 p. 307-319, 1999.

PATTERSON, D. T. Comparative ecophysiology of weeds and crops. In: DUKE, S. O. Reproduction an ecophysiology. Boca Raton: Weed Physiology. v. 1, 1985. p. 101-129.

RODRIGUES, B. N.; ALMEIDA, F. S. Guia de herbicidas. 4.ed. Londrina: Edição dos Autores, 1998. 648 p.

RODRIGUES, M. B.; KIEHL, J. C. Volatilização de amônia após emprego de uréia em diferentes doses e modos de aplicação. R. Bras. Ci. Solo, v. 10, p. 37-43, 1986.

SOCIEDADE BRASILEIRA DA CIÊNCIA DAS PLANTAS DANINHAS - SBCPD. Procedimentos para instalação, avaliação e análise de experimentos com herbicidas. Londrina: SBCPD, 1995. $42 \mathrm{p}$.

TENUTA, M.; BEAUCHAMP, E. G. Denitrification following a herbicide application to a grass sward. Can. J. Soil Sci., v. 76, p. 15-22, 1996.

TIEDJE, J. M. Denitrification. In: Methods of soil analysis. Chemical and microbiological properties. Madison: ASA-SSSA, 1982. Part 2. p. 1011-1026. (Agronomy Monograph)

VOLZ, M. G. Infestations of yellow nutsedge in cropped soil: effects on soil nitrogen availability to the crop and associated $\mathrm{N}$ transforming bacterial populations. Agro-Ecosyst., v. 3, p. 313-319, 1977.

YAMADA, T. Adubação nitrogenada do milho. Como melhorar a eficiência. Piracicaba: Associação Brasileira para Pesquisa da Potassa e do Fosfato, 1995. 4 p. (Informações Agronômicas, 71).

YAMADA, T. Adubação nitrogenada do milho. Quanto, como e quando aplicar. Piracicaba: Associação Brasileira para Pesquisa da Potassa e do Fosfato. 1996. 5 p. (Informações Agronômicas, 74).

YAMADA, T.; ABDALLA, S. R. S. Como melhorar a eficiência da adubação nitrogenada do milho. Associação Brasileira para Pesquisa da Potassa e do Fosfato. 2000. 5 p. (Informações Agronômicas, 91). 